\title{
Obama sparks an ideological donnybrook with his push to compare medical treatments
}

$\mathrm{T}$ he proposition sounds simple: pick a disease, study ways to treat it and see which works best.

Yet President Barack Obama's proposal to do a great deal of that has set off a political tempest in the United States.

Obama is moving aggressively on multiple fronts to reform a health care system that leaves more than 40 million people uninsured. As part of that overhaul, he is proposing to spur comparative effectiveness research, a long-existing but largely plodding area of medical inquiry.

His push has got conservative radio commentator Rush Limbaugh in fullthroated roar, liberals firing back in agitated blogs, and an assortment of patient advocates and medical professionals caught in between.

Obama won a commitment for US $\$ 1.1$ billion in comparative effectiveness research in his economic stimulus package and plans to set up a council to coordinate the studies. He's more than tripling the amount spent by the Bush administration toward the same goal.

Like much else Obama is doing in health care, the research is meant to be integrated into the fast-expanding realm of electronic record-keeping. The idea is to give doctors instant access to the latest and best practices as research uncovers the drug or procedure most likely to make patients well.

Advocates anticipate a gain in medical understanding as researchers probe questions like: Are some oral diabetes medications better than others? Does reasonably priced physical therapy, cortisone or acupuncture outperform expensive surgery when treating a rotator cuff tear?

Opponents worry the answers may come at too great a cost. The fear: It will lead to decisions driven by the dollar as limits are drawn on therapies the government and private insurers will cover. A related risk, critics contend, is that research that points to the most effective therapy for the average patient will downgrade treatments of particular value to segments of the population minorities, women, the elderly and the poor, among others.

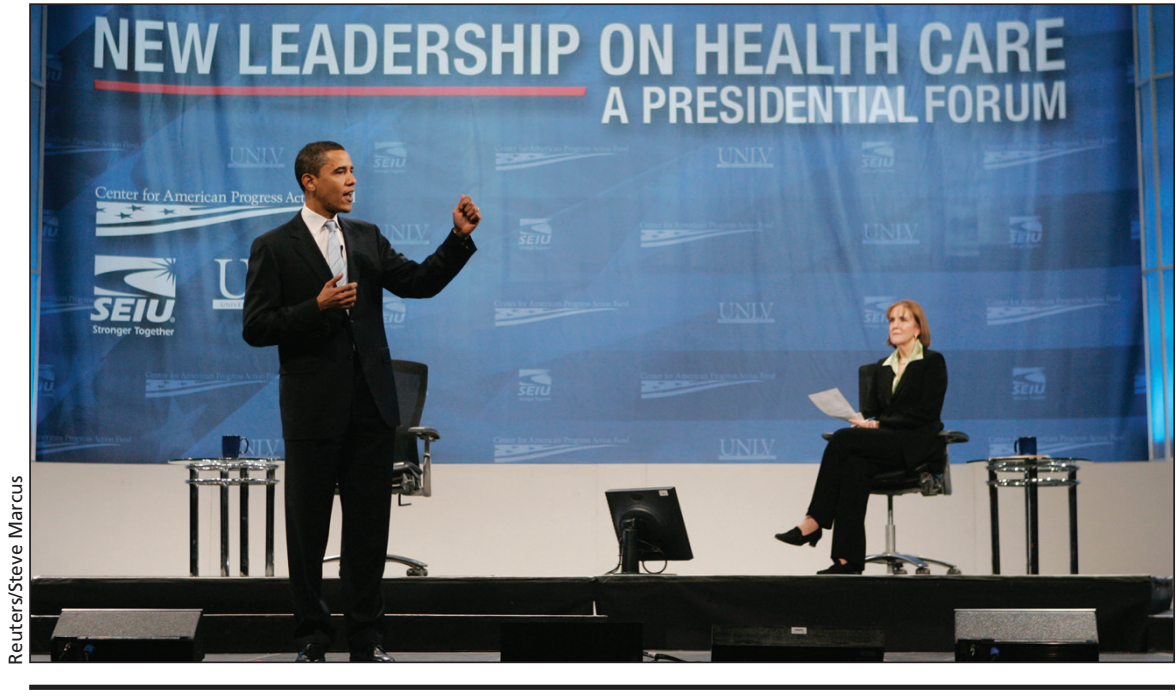

US President Barack Obama tripled funding for research comparing therapies.

To address such concerns, Congress wrote into law that the 15 -member council will have no authority to mandate coverage or set policy for public or private insurers. The question is whether that wall between research and bottom lines will - or even should survive these hard times. The impulse to save money any way possible is intense. Obama is advocating huge cuts in Medicaid and Medicare, the public insurance programs for the poor and elderly, to help pay for his US\$634billion, 10-year down payment on universal coverage.

Opposition to comparative effectiveness research has come primarily from the right, which is alert if not hypersensitive to anything resembling rationing.

Limbaugh has railed against it, and Senator Dr. Tom Coburn, a Republican from Oklahoma, warns that it will lay the groundwork for a "Soviet-style Federal Health Board that will put bureaucrats and politicians in charge."

He says, "I believe we should trust doctors and patients, not politicians and lobbyists, to make decisions about the cost and effectiveness of health care products and treatments."

From the left, Dr. Howard Dean, a former Democratic Party chairman, calls the criticism "claptrap."
"If an inexpensive pill that has been around a long time works substantially better than a brand new, highly advertised and thus far more expensive pill - doctors should have that information at hand when we prescribe medications to our patients," he wrote on The Huffington Post, an Internet newspaper.

Altogether, the debate has come as a reminder that everyone thinks the American health care system is broken until someone tries to fix it.

Medical societies and patient activists have generally endorsed the research effort while trying to shape it more to their interests. They share some of the qualms of conservatives.

Comparative effectiveness research "should not encourage a generalized, 'one-size-fits-all' approach," Kathryn M. Pontzer, vice-president of health policy for the Heart Rhythm Society, told congressional leaders. "Rather, it is necessary to design studies and communicate results in ways that reflect variation in individual patient needs, that help patients and doctors make informed choices, and account for differences among patients including comorbidities, sex, race and ethnicity." - Cal Woodward, Washington, DC

DOI: $10.1503 / \mathrm{cmaj} .090483$ 